\title{
HMGB1 as a therapeutic target in spinal cord injury: A hypothesis for novel therapy development (Review)
}

\author{
KIYOSHI KIKUCHI $^{1 *}$, HISAAKI UCHIKADO ${ }^{2 *}$, NAOKI MIURA ${ }^{6}$, YOKO MORIMOTO ${ }^{3}$, TAKASHI ITO ${ }^{4}$, \\ SALUNYA TANCHAROEN $^{5}$, KEI MIYATA ${ }^{4}$, ROKUDAI SAKAMOTO $^{1}$, CHIEMI KIKUCHI $^{7}$, NARUMI IIDA $^{8}$, \\ NAOTO SHIOMI ${ }^{9}$, TERUKAZU KURAMOTO ${ }^{10}$, NAOHISA MIYAGI ${ }^{1}$ and KO-ICHI KAWAHARA ${ }^{4,11}$ \\ ${ }^{1}$ Department of Neurosurgery, Yame Public General Hospital, Yame 834-0034; ${ }^{2}$ Department of Neurosurgery, \\ Kurume University School of Medicine, Kurume 830-0011; ${ }^{3}$ Department of Restorative Dentistry and Endodontology, \\ Kagoshima University Graduate School of Medical and Dental Sciences, Kagoshima 890-8544; \\ ${ }^{4}$ Division of Laboratory and Vascular Medicine, Field of Cardiovascular and Respiratory Disorders, \\ Department of Advanced Therapeutics, Kagoshima University, Graduate School of Medical and Dental Sciences, \\ Kagoshima 890-8520, Japan; ${ }^{5}$ Department of Pharmacology, Faculty of Dentistry, Mahidol University, Rajthevee, \\ Bangkok 10400, Thailand; ${ }^{6}$ Veterinary Teaching Hospital and Laboratory of Veterinary Diagnostic Imaging, \\ Faculty of Agriculture, Kagoshima University, Kagoshima 890-0065; ${ }^{7}$ Department of Rehabilitation, \\ Nishida Koutoku Hospital, Saiki, Oita 876-0047; ${ }^{8}$ Research Laboratory, Kohjin Co., Ltd., Saiki, Oita 876-8580; \\ ${ }^{9}$ Emergency Department, Saiseikai Shiga Hospital, Rittou, Shiga 520-3046; ${ }^{10}$ Department of Neurosurgery, \\ Omuta City General Hospital, Omuta, Fukuoka 836-8567; ${ }^{11}$ Laboratory of Functional Foods, Department of \\ Biomedical Engineering, Osaka Institute of Technology, Asahi Ward, Osaka City, Osaka 535-8585, Japan
}

Received April 28, 2011; Accepted June 29, 2011

DOI: $10.3892 / \mathrm{etm} .2011 .310$

\begin{abstract}
Historically, clinical outcomes following spinal cord injury (SCI) have been dismal. Severe SCI leads to devastating neurological deficits, and there is no treatment available that restores the injury-induced loss of function to a degree that an independent life can be guaranteed. To address all the issues associated with SCI, a multidisciplinary approach is required, as it is unlikely that a single approach, such as surgical intervention, pharmacotherapy or cellular transplantation, will suffice. High mobility group box 1 (HMGB1) is an inflammatory cytokine. Various studies have shown that HMGB1 plays a critical role in SCI and that inhibition of HMGB1 release may be a novel therapeutic target for SCI and may support spinal cord repair. In addition, HMGB1 has been associated with graft rejection in the early phase. Therefore, HMGB1 may be a promising therapeutic target for SCI transplant
\end{abstract}

Correspondence to: Dr Ko-ichi Kawahara, Division of Laboratory and Vascular Medicine, Field of Cardiovascular and Respiratory Disorders, Department of Advanced Therapeutics, Kagoshima University Graduate School of Medical and Dental Sciences, 8-35-1 Sakuragaoka, Kagoshima 890-8520, Japan

E-mail: telo@m3.kufm.kagoshima-u.ac.jp

*Contributed equally

Key words: high mobility group box 1, spinal cord injury, transplantation patients. We hypothesize that inhibition of HMGB1 release rescues patients with SCI. Taken together, our findings suggest that anti-HMGB1 monoclonal antibodies or short hairpin RNA-mediated HMGB1 could be administered for spinal cord repair in SCI patients.

\section{Contents}

1. Introduction

2. HMGB1 as a therapeutic target in various diseases

3. HMGB1 in spinal cord injury

4. HMGB1 in transplantation

5. Hypothesis

\section{Introduction}

One of the most serious clinical conditions is spinal cord injury (SCI), the incidence of which has been increasing yearly (1). Spinal cord repair is a problem that has long puzzled neuroscientists $(2,3)$. The repair of the injured human spinal cord with resultant functional recovery is one of the major challenges of contemporary neuroscience (4). Although the mortality rate of SCI has declined to less than $5 \%$, the disability rate associated with SCI remains high (1). One of the most destructive complications after SCI is paraplegia, which has been a constant challenge in clinical medicine (1). Facilitating recovery of spinal cord structure and function after SCI is of great interest to neuroscientists (1). Failure of the spinal cord to regenerate and undergo 
reconstruction after SCI can be attributed to the extremely limited regenerative capacity of most central nervous system (CNS) axons as well as the hostile environment of the adult CNS, with astroglial scars forming within lesioned areas (1).

Over the past 20 years, the survival rate and long-term outcome of patients with SCI has improved, with advances in both medical and surgical treatment (5). However, the efficacy and timing of these adjuvant treatments remain controversial (5). There has been a tremendous increase in the number of basic science and clinical studies on SCI (5). The pathophysiology of SCI is complex, multifactorial and multiphasic (4). Current areas of investigation involve early acute management, including early surgical intervention, as well as new pharmacotherapy and cellular transplantation strategies (5). Transplantation of various cells, such as neural stem cells, human embryonic stem cells, olfactory ensheathing cells, olfactory mucosa, bone marrow stromal cells and induced pluripotent stem cells, is not sufficient for spinal cord repair and is not sufficiently widespread in clinical situations (3,6-15). It is unlikely that a single approach uniformly addresses all of the issues associated with SCI (5). Thus, a multidisciplinary approach is required (5).

\section{HMGB1 as a therapeutic target in various diseases}

High mobility group box 1 (HMGB1) has pleiotropic effects both inside and outside cells. In the nucleus, HMGB1 bends DNA and promotes the assembly of other nuclear proteins (16). Extracellular HMGB1 released from necrotic or activated cells induces cell permeability, cell recruitment, cell-cell attachment, cytokine production (tumor necrosis factor- $\alpha$, interleukin- 8 and C-reactive protein), T-cell activation, T-helper 1-cell polarization, dendritic-cell maturation, tissue regeneration and coagulant activation (2,17-24). Once secreted, HMGB1 induces inflammatory responses by the transduction of cellular signals through its receptors, such as TLR2, TLR4 $(22,25,26)$ and receptor for advanced glycation end products (RAGE) $(17,27,28)$. HMGB1 levels are markedly increased during severe sepsis in humans and animals, and administration of neutralizing HMGB1-specific antibodies prevents lethality from sepsis (29). Elevated HMGB1 levels characterize various acute and chronic diseases and are implicated in inflammation and tissue injury. In addition, HMGB1 contributes to the pathogenesis of disorders of the brain, heart, liver, lungs, gut, pancreas, joints, blood vessels and periodontium, and is implicated in graft rejection in transplantation as well as sepsis (18-20,23,29-42). Furthermore, the blockade of HMGB1 release using an anti-HMGB1 monoclonal antibody or short hairpin (sh) RNA-mediated HMGB1 has already been shown to be effective in animal models of cancer, rheumatoid arthritis, cerebral infarction, myocardial infarction, hepatic ischemia, acute pancreatitis, hemorrhagic shock and sepsis $(29,34,36,43-48)$. Thus, HMGB1 is a novel inflammatory cytokine that is included in the 'alarmin' family, a group of endogenous factors released into the extracellular space, which activate the inflammatory response through the engagement of membrane receptors $(49,50)$.

\section{HMGB1 in spinal cord injury}

Recently, HMGB1 has been shown to be elevated in the spinal cord tissue of rodents with spinal cord compression injury and is associated with neuronal cell apoptosis $(51,52)$. Furthermore, HMGB1 has been shown to be elevated in both the spinal cord tissue and the serum of rodents with spinal cord ischemic injury $(53,54)$. Moreover, melatonin, ethyl pyruvate and hydrogen gas were found to reduce motor neuron apoptosis, improve motor dysfunction and attenuate the release of HMGB1 in rodents with SCI $(51,53,54)$. Previous studies have implicated that HMGB1 directly induces apoptosis in neural cells $(32,33)$, aggravates infarction volume and exacerbates the neurological deficit in transient cerebral ischemia in rats $(36,55)$.

It is known that the mode of delayed neuronal cell death after SCI is apoptosis $(52,56)$. Apoptosis is influenced by several injury-promoting factors which include pro-inflammatory cytokines $(52,56)$. Inhibition of apoptosis promotes neurologic improvement following SCI $(52,56)$. Therefore, it is expected that inhibition of HMGB1 release may be a novel therapeutic strategy for treating SCI as well as various acute and chronic diseases.

\section{HMGB1 in transplantation}

Several lines of evidence suggest that HMGB1 may play a major role in graft rejection. First, administration of thrombin and HMGB1 together in rats was found to result in excessive fibrin deposition, demonstrating pro-coagulant activity (19), and to trigger the RAGE signaling pathway, in which HMGB1 is a ligand, to activate complement (57), suggesting that HMGB1 may contribute to both vascular events and complement activation in acute rejection. Second, treatment of allograft recipients with RAGE, an anti-HMGB1 antibody or HMGB1 box-A (amino-terminal region), which specifically blocks endogenous HMGB1, was found to significantly prolong the survival of transplanted hearts in murine models $(58,59)$. Furthermore, neutralization with an anti-HMGB1 antibody has been suggested to prevent fibrogenesis in postorthotopic liver transplantation liver grafts (60), and treatment with an HMGB1-specific antibody prevented early islet graft loss following islet transplantation in mice (61). Therefore, it is expected that HMGB1 may become a novel therapeutic target for transplant patients following SCI, as well as other transplantations.

\section{Hypothesis}

The present hypothesis focuses on HMGB1 as a therapeutic target in spinal cord repair. Currently, there is no effective treatment for SCI. First, it is necessary to study the outcome of anti-HMGB1 monoclonal antibody or shRNA-mediated HMGB1 administration in animal models with SCI. Second, it is necessary to study the outcome of anti-HMGB1 monoclonal antibody or shRNA-mediated HMGB1 administration in animals that have been transplanted with various types of cells after SCI. We hypothesize that inhibition of HMGB1 as a therapeutic target for the treatment of SCI may support spinal cord repair and may be advantageous in the treatment of SCI in a clinical setting. We suggest that patients with SCI should be administered anti-HMGB1 monoclonal antibodies or shRNA-mediated HMGB1, and we predict that administration will result in positive outcomes for SCI patients. Clearly, further studies are required to confirm the effects of anti- 
HMGB1 monoclonal antibody or shRNA-mediated HMGB1 administration on patient outcomes.

\section{References}

1. McDonald JW and Sadowsky C: Spinal-cord injury. Lancet 359 417-425, 2002

2. Andersson U, Wang H, Palmblad K, et al: High mobility group 1 protein (HMG-1) stimulates proinflammatory cytokine synthesis in human monocytes. J Exp Med 192: 565-570, 2000.

3. Ao Q, Wang AJ, Chen GQ, Wang SJ, Zuo HC and Zhang XF: Combined transplantation of neural stem cells and olfactory ensheathing cells for the repair of spinal cord injuries. Med Hypotheses 69: 1234-1237, 2007.

4. Rosenfeld JV, Bandopadhayay P, Goldschlager T and Brown DJ: The ethics of the treatment of spinal cord injury: stem cell transplants, motor neuroprosthetics, and social equity. Top Spinal Cord Inj Rehabil 14: 76-88, 2008.

5. Gupta R, Bathen ME, Smith JS, Levi AD, Bhatia NN and Steward O: Advances in the management of spinal cord injury. J Am Acad Orthop Surg 18: 210-222, 2010.

6. Choi D, Law S, Raisman G and Li D: Olfactory ensheathing cells in the nasal mucosa of the rat and human. Br J Neurosurg 22: 301-302, 2008

7. Couzin J: Biotechnology. Celebration and concern over U.S. trial of embryonic stem cells. Science 323: 568, 2009.

8. Iwatsuki K, Yoshimine T, Kishima H, et al: Transplantation of olfactory mucosa following spinal cord injury promotes recovery in rats. Neuroreport 19: 1249-1252, 2008.

9. Li Y, Yamamoto M, Raisman G, Choi D and Carlstedt T: An experimental model of ventral root repair showing the beneficial effect of transplanting olfactory ensheathing cells. Neurosurgery 60: 734-741, 2007

10. Lima C, Pratas-Vital J, Escada P, Hasse-Ferreira A, Capucho C and Peduzzi JD: Olfactory mucosa autografts in human spinal cord injury: a pilot clinical study. J Spinal Cord Med 29: 191-206, 2006.

11. Okano H: Strategies toward CNS-regeneration using induced pluripotent stem cells. Genome Inform 23: 217-220, 2009.

12. Raisman G: Repair of spinal cord injury by transplantation of olfactory ensheathing cells. C R Biol 330: 557-560, 2007.

13. Raisman G and Li Y: Repair of neural pathways by olfactory ensheathing cells. Nat Rev Neurosci 8: 312-319, 2007.

14. Tsuji O, Miura K, Okada Y, et al: Therapeutic potential of appropriately evaluated safe-induced pluripotent stem cells for spinal cord injury. Proc Natl Acad Sci USA 107: 12704-12709, 2010.

15. Zurita $M$ and Vaquero J: Functional recovery in chronic paraplegia after bone marrow stromal cell transplantation. Neuroreport 15: 1105-1108, 2004.

16. Agresti A and Bianchi ME: HMGB proteins and gene expression. Curr Opin Genet Dev 13: 170-178, 2003.

17. Dumitriu IE, Baruah P, Valentinis B, et al: Release of high mobility group box 1 by dendritic cells controls $\mathrm{T}$ cell activation via the receptor for advanced glycation end products J Immunol 174: 7506-7515, 2005.

18. Inoue $\mathrm{K}$, Kawahara K, Biswas KK, et al: HMGB1 expression by activated vascular smooth muscle cells in advanced human atherosclerosis plaques. Cardiovasc Pathol 16: 136-143, 2007.

19. Ito T, Kawahara K, Nakamura T, et al: High-mobility group box 1 protein promotes development of microvascular thrombosis in rats. J Thromb Haemost 5: 109-116, 2007.

20. Morimoto Y, Kawahara KI, Tancharoen S, et al: Tumor necrosis factor-alpha stimulates gingival epithelial cells to release high mobility-group box 1. J Period Res 43: 76-83, 2008.

21. Rovere-Querini P, Capobianco A, Scaffidi P, et al: HMGB1 is an endogenous immune adjuvant released by necrotic cells. EMBO Rep 5: 825-830, 2004

22. Scaffidi P, Misteli T and Bianchi ME: Release of chromatin protein HMGB1 by necrotic cells triggers inflammation. Nature 418: 191-195, 2002.

23. Taniguchi N, Kawahara K, Yone K, et al: High mobility group box chromosomal protein 1 plays a role in the pathogenesis of rheumatoid arthritis as a novel cytokine. Arthritis Rheum 48: 971-981, 2003.

24. Yang D, Chen Q, Yang H, Tracey KJ, Bustin M and Oppenheim JJ: High mobility group box-1 protein induces the migration and activation of human dendritic cells and acts as an alarmin. J Leukocyte Biol 81: 59-66, 2007.
25. Park JS, Gamboni-Robertson F, He Q, et al: High mobility group box 1 protein interacts with multiple Toll-like receptors. Am J Physiol 290: C917-C924, 2006.

26. Park JS, Svetkauskaite D, He Q, et al: Involvement of toll-like receptors 2 and 4 in cellular activation by high mobility group box 1 protein. J Biol Chem 279: 7370-7377, 2004.

27. Hori O, Brett J, Slattery T, et al: The receptor for advanced glycation end products (RAGE) is a cellular binding site for amphoterin. Mediation of neurite outgrowth and co-expression of rage and amphoterin in the developing nervous system. J Biol Chem 270: 25752-25761, 1995.

28. Kokkola R, Andersson A, Mullins G, et al: RAGE is the major receptor for the proinflammatory activity of HMGB1 in rodent macrophages. Scand J Immunol 61: 1-9, 2005.

29. Wang H, Bloom O, Zhang M, et al: HMG-1 as a late mediator of endotoxin lethality in mice. Science 285: 248-251, 1999.

30. Dumitriu IE, Baruah P, Manfredi AA, Bianchi ME and Rovere-Querini P: HMGB1: guiding immunity from within. Trends Immunol 26: 381-387, 2005.

31. Goldstein RS, Gallowitsch-Puerta M, Yang L, et al: Elevated high-mobility group box 1 levels in patients with cerebral and myocardial ischemia. Shock 25: 571-574, 2006.

32. Kikuchi K, Kawahara K, Biswas KK, et al: Minocycline attenuates both OGD-induced HMGB1 release and HMGB1-induced cell death in ischemic neuronal injury in PC12 cells. Biochem Biophys Res Commun 385: 132-136, 2009.

33. Kikuchi K, Kawahara K, Tancharoen S, et al: The free radical scavenger edaravone rescues rats from cerebral infarction by attenuating the release of high-mobility group box-1 in neuronal cells. J Pharmacol Exper Ther 329: 865-874, 2009.

34. Kim JB, Sig Choi J, Yu YM, et al: HMGB1, a novel cytokine-like mediator linking acute neuronal death and delayed neuroinflammation in the postischemic brain. J Neurosci 26: 6413-6421, 2006.

35. Lindstrom O, Tukiainen E, Kylanpaa L, et al: Circulating levels of a soluble form of receptor for advanced glycation end products and high-mobility group box chromosomal protein 1 in patients with acute pancreatitis. Pancreas 38: e215-e220, 2009.

36. Liu K, Mori S, Takahashi HK, et al: Anti-high mobility group box 1 monoclonal antibody ameliorates brain infarction induced by transient ischemia in rats. FASEB J 21: 3904-3916, 2007.

37. Lotze MT and Tracey KJ: High-mobility group box 1 protein (HMGB1): nuclear weapon in the immune arsenal. Nat Rev 5: $331-342,2005$.

38. Nakahara T, Tsuruta R, Kaneko T, et al: High-mobility group box 1 protein in CSF of patients with subarachnoid hemorrhage. Neurocrit Care 11: 362-368, 2009.

39. Qiu J, Nishimura M, Wang Y, et al: Early release of HMGB-1 from neurons after the onset of brain ischemia. J Cereb Blood Flow Metab 28: 927-938, 2008

40. Takano K, Shinoda M, Tanabe M, et al: Protective effect of high-mobility group box 1 blockade on acute liver failure in rats: (HMGB1 blockade for rat acute liver failure). Shock 34: 573-579, 2010.

41. Ulloa L and Messmer D: High-mobility group box 1 (HMGB1) protein: friend and foe. Cytokine Growth Factor Rev 17: 189-201, 2006.

42. Van Zoelen MA, Ishizaka A, Wolthuls EK, Choi G, van der Poll T and Schultz MJ: Pulmonary levels of high-mobility group box 1 during mechanical ventilation and ventilator-associated pneumonia. Shock 29: 441-445, 2008.

43. Kohno T, Anzai T, Naito K, et al: Role of high-mobility group box 1 protein in post-infarction healing process and left ventricular remodelling. Cardiovasc Res 81: 565-573, 2009.

44. Maeda S, Hikiba Y, Shibata W, et al: Essential roles of highmobility group box 1 in the development of murine colitis and colitis-associated cancer. Biochem Biophys Res Commun 360: 394-400, 2007

45. Sawa H, Ueda T, Takeyama Y, et al: Blockade of high mobility group box-1 protein attenuates experimental severe acute pancreatitis. World J Gastroenterol 12: 7666-7670, 2006.

46. Ulloa L, Batliwalla FM, Andersson U, Gregersen PK and Tracey KJ: High mobility group box chromosomal protein 1 as a nuclear protein, cytokine, and potential therapeutic target in arthritis. Arthritis Rheum 48: 876-881, 2003.

47. Watanabe T, Kubota S, Nagaya M, et al: The role of HMGB-1 on the development of necrosis during hepatic ischemia and hepatic ischemia/reperfusion injury in mice. J Surg Res 124: 59-66, 2005. 
48. Yang R, Harada T, Mollen KP, et al: Anti-HMGB1 neutralizing antibody ameliorates gut barrier dysfunction and improves survival after hemorrhagic shock. Mol Med 12: 105-114, 2006.

49. Bianchi ME: DAMPs, PAMPs and alarmins: all we need to know about danger. J Leukocyte Biol 81: 1-5, 2007.

50. Oppenheim JJ and Yang D: Alarmins: chemotactic activators of immune responses. Curr Opin Immunol 17: 359-365, 2005.

51. Esposito E, Genovese T, Caminiti R, Bramanti P, Meli R and Cuzzocrea S: Melatonin reduces stress-activated/mitogenactivated protein kinases in spinal cord injury. J Pineal Res 46: 79-86, 2009.

52. Kawabata H, Setoguchi T, Yone K, et al: High mobility group box 1 is upregulated after spinal cord injury and is associated with neuronal cell apoptosis. Spine 35: 1109-1115, 2010.

53. Huang Y, Xie K, Li J, et al: Beneficial effects of hydrogen gas against spinal cord ischemia-reperfusion injury in rabbits. Brain Res 1378: 125-136, 2010.

54. Wang Q, Ding Q, Zhou Y, et al: Ethyl pyruvate attenuates spinal cord ischemic injury with a wide therapeutic window through inhibiting high-mobility group box 1 release in rabbits. Anesthesiology 110: 1279-1286, 2009.

55. Faraco G, Fossati S, Bianchi ME, et al: High mobility group box 1 protein is released by neural cells upon different stresses and worsens ischemic neurodegeneration in vitro and in vivo. J Neurochem 103: 590-603, 2007.
56. Crowe MJ, Bresnahan JC, Shuman SL, Masters JN and Beattie MS: Apoptosis and delayed degeneration after spinal cord injury in rats and monkeys. Nat Med 3: 73-76, 1997.

57. Johnson LV, Leitner WP, Rivest AJ, Staples MK, Radeke MJ and Anderson DH: The Alzheimer's A beta-peptide is deposited at sites of complement activation in pathologic deposits associated with aging and age-related macular degeneration. Proc Natl Acad Sci USA 99: 11830-11835, 2002.

58. Huang Y, Yin H, Han J, et al: Extracellular HMGB1 functions as an innate immune-mediator implicated in murine cardiac allograft acute rejection. Am J Transplant 7: 799-808, 2007.

59. Moser B, Szabolcs MJ, Ankersmit HJ, et al: Blockade of RAGE suppresses alloimmune reactions in vitro and delays allograft rejection in murine heart transplantation. Am J Transplant 7: 293-302, 2007.

60. Kao YH, Jawan B, Goto S, et al: High-mobility group box 1 protein activates hepatic stellate cells in vitro. Transplant Proc 40: 2704-2705, 2008.

61. Matsuoka N, Itoh T, Watarai H, et al: High-mobility group box 1 is involved in the initial events of early loss of transplanted islets in mice. J Clin Invest 120: 735-743, 2010. 